\title{
Termal ve ultrases proseslerinin adaçayı ve hibiskus ekstraktlarının bazı kalite özellikleri üzerine etkisi
}

\section{Effect of thermal and ultrasound processes on some quality characteristics of sage and hibiscus extracts}

\author{
Cüneyt DINÇER ${ }^{1,2}$ (i) \\ ${ }^{1}$ Akdeniz Üniversitesi, Gıda Güvenliği ve Tarımsal Araştırmalar Merkezi, 07058, Antalya, Türkiye \\ ${ }^{2}$ Akdeniz Üniversitesi, Finike Meslek Yüksekokulu, Gıda İşleme Bölümü, 07740, Antalya, Türkiye \\ Sorumlu yazar (Corresponding author): C. Dinçer, e-posta (e-mail): cdincer@akdeniz.edu.tr
}

\section{MAKALE BİLGİSİ}

Alınış tarihi 28 Ağustos 2020

Düzeltilme tarihi 08 Mart 2021

Kabul tarihi 09 Mart 2021

\section{Anahtar Kelimeler:}

Adaçayı

Hibiskus

Termal proses

Ultrases

Kalite özellikleri

\begin{abstract}
$\ddot{\mathbf{o z}}$
$\mathrm{Bu}$ çalışmada termal ve ultrases uygulamalarının adaçayı ve hibiskus ekstraktlarının bazı kalite özellikleri üzerine etkisi araştırılmıştır. Bu amaçla $85^{\circ} \mathrm{C}$ 'de su banyosunda, ultrasonik banyoda $\left(<40^{\circ} \mathrm{C}, 0.031 \mathrm{~W} \mathrm{~mL}^{-1}\right.$ Akustik Güç Yoğunluğu) ve problu ultrases sisteminde $\left(<40^{\circ} \mathrm{C}, 1.337 \mathrm{~W} \mathrm{~mL}^{-1}\right.$ Akustik Güç Yoğunluğu) uygulamalar gerçekleştirilmiştir. Uygulama sürecinde $5,10,15$ ve $20 \mathrm{dk}$ zaman aralıkları ile örnekleme yapılmış ve örneklerde pH, iletkenlik, renk, bulanıklık ve toplam fenolik madde içeriği analizleri yapılmıştır. Adaçayı (1.3 ${ }^{\circ} \mathrm{Bx}$ ) ekstraktlarının $\mathrm{pH}$, iletkenlik ve toplam fenolik madde içerikleri sırasıyla 5.66-5.73, $1.61-1.63 \mathrm{~ms} \mathrm{~cm}^{-1}$ ve $2.58-2.71 \mathrm{~g} \mathrm{~L}^{-1} \mathrm{GAE}$ arasında belirlenirken, hibiskus ekstraktlarında bu değerler sırasıyla 2.28-2.41, 4.05-4.16 ms cm-1 ve 0.80-0.84 $\mathrm{g} \mathrm{L}^{-1} \mathrm{GAE}$ arasında değişim göstermiştir. Uygulamaların genel olarak bulanıklık değeri dışında önemli bir değişime neden olmadığı gözlenmiştir. Problu ultrases sistemi ile 20 dakikalık uygulamadan sonra adaçayı ekstraktlarında bulanıklık değeri 117 NTU'dan 230 NTU'ya yükselirken, bu değer hibiskus ekstraktlarında 58.95 NTU'dan 153.6 NTU'ya yükselmiştir.
\end{abstract}

\section{ARTICLE INFO}

Received 28 August 2020

Received in revised form 08 March 2021

Accepted 09 March 2021

\section{Keywords:}

Sage

Hibiscus

Thermal process

Ultrasound

Quality properties

\begin{abstract}
In this study, the effects of thermal and ultrasound applications on some quality properties of sage and hibiscus extracts were investigated. For this purpose, applications were carried out in $85^{\circ} \mathrm{C}$ water bath, ultrasonic bath $\left(<40^{\circ} \mathrm{C}, 0.031 \mathrm{~W} \mathrm{~mL}^{-1}\right.$ Acoustic Power Density) and probe ultrasound system $\left(<40^{\circ} \mathrm{C}, 1.337 \mathrm{~W} \mathrm{~mL}^{-1}\right.$ Acoustic Power Density). The samples were taken at, 5th, 10th, 15th, 20th minutes during the applications and analysis of $\mathrm{pH}$, conductivity, color, turbidity and total phenolic content of the samples were performed. While $\mathrm{pH}$, conductivity and total phenolic content of sage extracts $\left(1.3^{\circ} \mathrm{Bx}\right)$ were determined between 5.66-5.73, $1.61-1.63 \mathrm{~ms} \mathrm{~cm}^{-1}$ and $2.58-2.71 \mathrm{~g} \mathrm{~L}^{-1} \mathrm{GAE}$, respectively, these values were changed between $2.28-2.41,4.05-4.16 \mathrm{~ms} \mathrm{~cm}^{-1}$ and $0.80-0.84 \mathrm{~g} \mathrm{~L}^{-1} \mathrm{GAE}$ in hibiscus extracts, respectively. It has been observed that the applications generally do not cause any significant change except for the turbidity value. While the turbidity increased from the 117 NTU to 230 NTU in sage extracts, this value increased from the 58.95 NTU to $153.6 \mathrm{NTU}$ in hibiscus extracts after 20 minutes of application with the probe ultrasound system.
\end{abstract}

\section{Giriş}

Son yıllarda yapılan çalışmalarla tıbbi ve aromatik bitkilerin içerdiği biyoaktif bileşenlerin sağlık açısından önemli faydaları olduğunun vurgulanması bu bitkilerin değerini ve tüketimini arttırmıştır. Bu kapsamda adaçayı ve hibiskus içerdiği biyoaktif bileşenlerin yanı sıra sahip oldukları aroma ve göz alıcı renk maddeleri sayesinde son y1llarda kozmetikten, parfümeriye, kimyadan gıdaya kadar pek çok sektörde kullanım alanı bulabilmektedir (Dinçer ve ark. 2020; Dinçer 2020).
Ülkemizde adaçayı olarak bilinen Salvia cinsi bitkiler Lamiaceae familyasının en önemli üyeleri arasında yer almaktadır. Latince kökenli bir kelime olan Salvia "iyileştirmek" veya "tedavi etmek" anlamlarını taşımaktadır. Kökeni ve yayılış alanı Akdeniz çevresi olan Salvia cinsinin en iyi bilinen türü ise tıbbi adaçayı olarak da tanınan Salvia officinalis'tir (Tepe 2002; Baydar 2005). Ancak S. officinalis ülkemizde doğal olarak yetişmemekte, kültür koşullarında 
yetiştirilmektedir. Türkiye'de yaygın olarak bulunan ve ticari öneme sahip Salvia türlerinin başında ise Salvia fruticosa (sinonim S. triloba) gelmektedir (Baser 2002; Baydar 2005). S. fruticosa'nın önemli miktarda fenolikler ve terpenoidler gibi biyoaktif bileşenler içerdiği, anti-enflamatuar, antimikrobiyal ve antioksidan aktivitelerinin de çoğunlukla rosmarinik asit (fenolik) ve 1,8-sineole (terpenoid) ile ilişkili olduğu rapor edilmektedir (El-Sayed ve ark. 2001; Delamare ve ark. 2007; Şahin-Nadeem ve ark. 2013). Adaçayı kozmetik, parfümeri ve kimya endüstrisinde kullanımının yanında et yemeklerinde aroma verici baharat olarak ve özellikle bitki çayı olarak yaygın şekilde tüketilmektedir (Delamare ve ark. 2007; Yağcıoğlu 2015; Gezek ve ark. 2019).

Hibiskus (Hibiscus sabdariffa L.) bitkisi ise tropikal ve subtropikal iklimlerde yetiştirilebilen, Malvaceae familyasından, çalımsı bir bitkidir (Gedik 2014). Bitkinin ticari olarak önemli olan kısmı etli çanak yapraklarıdır (Gedik 2014). Hibiskus çanak yaprakları (kaliksleri) önemli miktarda karbonhidrat, protein, ham lif ve organik asit içermesi yanında hibiskusun ticari olarak önemi özellikle antosiyanin içeriğinden kaynaklanmaktadır (Cid-Ortega ve Guerrero-Beltrán 2015). Son dönemde yapılan çalışmalarda hibiskus ekstraktlarının, içerdiği biyoaktif maddelere bağlı olarak antioksidan, antibakteriyel, diüretik, ateş düşürücü, tansiyon düşürücü, antikolesterol ve antidiabetik özellikler gösterdiği bildirilmektedir (Da-CostaRocha ve ark. 2014; Cid-Ortega ve Guerrero-Beltrán 2015). Hibiskus gıda endüstrisinde bitki çayı, sıcak ve soğuk içecekler, reçel, şekerlemeler, dondurma, çikolata, tatlandırıcılar, puding ve pasta gibi ürünlerin hazırlanmasında kullanılmaktadır (DaCosta-Rocha ve ark. 2014; Cid-Ortega ve Guerrero-Beltrán 2015).

Adaçayı ve hibiskus gibi bitkisel kaynaklı ürünlerin gıda endüstrisinde istenen amaca uygun olarak değerlendirilebilmesi için ekstraksiyon, pastörizasyon, konsantrasyon vb. işlemlere tabi tutulması gerekmektedir. $\mathrm{Bu}$ doğrultuda gıda sanayiinde klasik termal yöntemlerinin kullanımı oldukça yaygındır. Ancak bu yöntemlerde, yüksek düzeyde çözgen kullanımının yanı sıra, süre ve sıcaklığa bağlı olarak ısıya hassas bileşenlerce zengin ürünlerde arzu edilmeyen olumsuzlukların meydana gelmesi yeni yöntemler ile ilgili çalışmaların önemini arttırmıştır. Bu kapsamda 1sıl işlemle kıyasla daha düşük sıcaklıklarda işlemlere imkan tanıyan ultrases gibi yöntemler ön plana çıkmaktadır (Ergün ve ark. 2013; Dinçer ve ark. 2020).

Ultrases, katı, sıvı ve gazlardan geçebilen, insanların duyma sınırı olan, frekansı $20 \mathrm{kHz}$ üzerindeki ses dalgaları olarak tanımlanabilmektedir (Condón ve ark. 2005; Dinçer ve Topuz 2018). Ultrases sıvı içerisinde uygulandığında sonikasyon olarak adlandırılabilmektedir (Tiwari ve Mason 2011). Sonikasyonun temel etki mekanizması ise kavitasyon ile açıklanmaktadır. Ses dalgası sıvının içerisinden geçerken boyuna dalgalar oluşturur ve ardışı olarak kasılıp gevşeme olayları gerçekleşir ve mikro kabarcıklar ile boşluklar oluşur. Sıv1 içindeki küçük kabarcıklar ultrases dalgalarının gevşemesıkışma hareketleri ile hızlı bir şekilde gelişmekte ve kritik bir değere ulaştığında patlamaktadır ki buna kavitasyon denir (Piyasena ve ark. 2003; Tiwari ve Mason 2011).

Son yıllarda ultrases işleminin adaçayı ve hibiskus gibi bitkilerin ekstraskiyonunda, ayrıca meyve suyu gibi soğuk içeceklerin pastörizasyonunda uygulanabilirliği ile ilgili önemli çalışmalar yürütülmektedir. Ancak özellikle son dönemde adaçayı ve hibiskus gibi bitkilerin soğuk içecek üretimindeki kullanımı önemli düzeyde artmasına rağmen, bu bitki ekstraklarının ultrases ile işlenmesini konu alan çalışmaların oldukça sınırlı olduğu görülmektedir. Bu noktadan hareketle bu çalışmanın amacı termal ve farklı ultrases sistemlerindeki uygulamaların adaçayı ve hibiskus ekstraktlarının bazı özellikleri üzerindeki etkilerinin belirlenmesidir.

\section{Materyal ve Yöntem}

\subsection{Materyal}

Çalışmada materyal olarak, sırasıyla 1.3 ve $2.3{ }^{\circ}$ Briks seviyesinde suda çözünür kuru madde içeriğine sahip adaçayı ve hibiskus ekstraktları kullanılmıştır. Ekstraktları hazırlamak için Antalya'da faaliyet gösteren bir aktardan temin edilen adaçayı (Salvia fruticosa) ve hibiskus (Hibiscus sabdariffa L.) bitkisinin kurutulmuş yaprakları kullanılmıştır. Örnekler blenderda (Beko BKK-2155 Maxi El Blendırı, Türkiye) ögütüldükten sonra elekler (Retsch, GmbH \& Co. KG, Almanya) yardımıyla partikül büyüklüğünün $\quad 0.5-1.0 \mathrm{~mm}$ arasında olmas1 sağlanmıştır. Ekstraksiyon işlemi örnek su oranı 4/100 olacak şekilde $75^{\circ} \mathrm{C}$ deki su banyosunda (Heidolph Hei VAP Precision, Almanya) $500 \mathrm{~d}$ dk-1 karıştırma hızındaki pervaneli karıştırıcı (MTOPS MS3040D Lab. Stirrer Kore) yardımıyla $30 \mathrm{dk}$ süreyle gerçekleştirilmiştir. Ardından elde edilen ekstraktlar kaba filtre kağıdından süzüldükten sonra denemelere kadar $+4^{\circ} \mathrm{C}$ 'de muhafaza edilmiştir. Refraktometre ile yapılan ölçüme göre adaçayı ve hibiskus esktraktlarının suda çözünür kuru madde içerikleri sırasıyla 1.3 ve $2.3^{\circ} \mathrm{Bx}$ olarak belirlenmiştir.

\subsection{Yöntem}

\subsubsection{Termal ve ultrases prosesleri}

Elde edilen çözeltilere termal ve ultrasonik işlemler uygulanmıştır. $\mathrm{Bu}$ amaçla termal proses $85^{\circ} \mathrm{C}$ 'deki su banyosunda (Heidolph Hei VAP Precision, Almanya) gerçekleştirilmiştir. İlk olarak ağzı vidalı kapaklı 100 mL'lik cam şişelere $50 \mathrm{~mL}$ örnek aktarılmıştır. Ardından su banyosundaki su seviyesi şişe içerisindeki çözelti seviyesinin üzerinde olacak şekilde ayarlanmıştır. Örneklemeler 5, 10, 15 ve $20 \mathrm{dk}$ zaman aralıkları ile su banyosundan ikişer şişenin alınmasıyla gerçekleştirilmiştir. Örneklerin merkez sıcaklıklarının $85^{\circ} \mathrm{C}^{\prime}$ ye yaklaşık $5.5 \mathrm{dk}$ içerisinde ulaştığı, harici olarak su banyosuna konulan örnek içerisindeki termokapıl ile belirlenmiştir.

Ultrasonik uygulamalar; problu sistem ve ultrasonik banyo olmak üzere iki farklı sistemde gerçekleştirilmiştir. Problu ultrases sisteminde uygulanan işlem $13 \mathrm{~mm}$ prop ve ultrasonik dönüştürücüye sahip $20 \mathrm{kHz}$ sabit freakansta çalışan ultrases cihazı (VC750, $750 \mathrm{~W}$, Sonics and Materials, Inc., Mewtown, Conn., A.B.D.) ile gerçekleştirilmiştir. Uygulamalar çift cidarlı beher $(100 \mathrm{~mL}$ hacimli, $4.2 \mathrm{~cm}$ iç çap ve $10.5 \mathrm{~cm}$ yüksekliğinde) içerisinde gerçekleştirilmiştir. İşlemin $40^{\circ} \mathrm{C}$ 'nin altında gerçekleştirilebilmesi için uygulamalar boyunca çift cidarlı beher içerisinden su banyosu (RW-3025 Lab Copanion, Kore) vasıtasıyla su sirkülasyonu sağlanmış ve örneklerin sıcaklığı K-tipi termokapıl (CHY 500K Thermometer, Taiwan) ile kontrol edilmiştir. Ultrases işlemi \%100 genlik seviyesinde beşer saniye aralıklar ile kesikli olarak uygulanmıştır. Ultrases probu örneklerin içerisine, sıçramaların ve köpük oluşumunun minimum olduğu, ön denemeler ile belirlenmiş $\sim 2.5 \mathrm{~cm}$ derinlikte daldırılmış ve ultrases uygulaması gerçekleştirilmiştir. Uygulama süresi $(5,10,15$ ve $20 \mathrm{dk}$ ) sonunda örnekler vidalı kapaklı 100 mL'lik cam şişelere aktarılmış ve analizlere kadar $+4^{\circ} \mathrm{C}$ 'de muhafaza edilmiştir. Akustik güç yoğunluğu (AGY) işlem gören sıvının $1 \mathrm{~mL}$ 'sine uygulanan enerjinin bir 
göstergesidir (Tiwari ve Mason 2011, Lee ve ark. 2013) ve bu ölçüm farklı ultrases sistemlerinin karşılaştırılabilmesi ve daha büyük kapasiteli sistemlerin planlanmasinda önem arz etmektedir. Bu çalışmada AGY, Tiwari ve Mason (2011)'ın rapor ettiği metoda göre kalorimetrik olarak belirlenmiş ve $1.337 \mathrm{~W} \mathrm{~mL} \mathrm{~m}^{-1}$ olarak hesaplanmıştır. $\mathrm{Bu}$ amaçla ultrases uygulaması sırasında suyun sıcaklığı $(\mathrm{T})$ zamanın bir fonksiyonu olarak termokapıl ile ölçülmüsşür. Zamana karşı sıcaklık verilerinden başlangıç sıcaklığının yükselişinin $\left(\mathrm{dT} \mathrm{dt}^{-1}\right)$ polinomal kurveye uygunluğu belirlenmiştir. Ultrasonik güç $(\mathrm{P})$ ve $\mathrm{AGY}\left(\mathrm{W} \mathrm{mL}^{-1}\right)$ değerleri aşağıdaki eşitlikler kullanarak hesaplanmıştır.

$$
\begin{aligned}
& P=m c_{p}\left(\frac{d T}{d t}\right)_{t=0} \\
& A G Y=\frac{P}{V}
\end{aligned}
$$

Eşitlikte yer alan, $\mathrm{P}=$ Ultrasonik güç $(\mathrm{W}), \mathrm{m}=$ Örneğin kütlesi (kg), $\mathrm{C}_{\mathrm{p}}=$ Suyun özgül 1 sis1 $\left(\mathrm{kJ} \mathrm{kg}^{-1{ }^{\circ}} \mathrm{C}^{-1}\right), \mathrm{dT} \mathrm{dt}^{-1}$ zamana bağlı sıcaklık değişimi (kurvenin eğimi) $\left({ }^{\circ} \mathrm{C} \mathrm{s}^{-1}\right)$, AGY akustik güç yoğunluğu $\left(\mathrm{W} \mathrm{mL}^{-1}\right)$ ve $\mathrm{V}$ örnek hacmidir $(\mathrm{mL})$.

Ultrasonik banyoda (Çalişkan Ultrasonic Cleaner, Türkiye) uygulama $40^{\circ} \mathrm{C}, 40 \mathrm{kHz}$ sabit frekansta ve $0.031 \mathrm{~W} \mathrm{~mL}^{-1}$ Akustik Güç Yoğunluğunda (AGY) gerçekleştirilmiştir. AGY, Tiwari ve Mason (2011)'ın rapor ettiği metoda göre problu sistemde olduğu gibi kalorimetrik olarak belirlenmiştir. Termal proseste olduğu gibi, $50 \mathrm{~mL}$ örnek ağzı vidalı kapaklı 100 mL'lik cam şişelere aktarılmıştır. Ultrasonik banyodaki su seviyesi şişe içerisindeki çözelti seviyesinin üzerinde olacak şekilde ayarlanmıștır. Örneklemeler $5,10,15$ ve $20 \mathrm{dk}$ zaman aralıkları ile ultrasonik banyodan ikişer şişenin alınmasıyla gerçekleştirilmiştir.

\subsubsection{Analizler}

\subsubsection{Suda çözünür kuru madde tayini (SÇKM)}

Örneklerin suda çözünebilir kuru madde miktarı refraktometre (PAL- $\alpha$ ATAGO, Tokyo, Japonya) ile oda sıcaklığında ölçülmüştür.

\subsubsection{2. $p H$ ve iletkenlik ölçümü}

Örneklerin $\mathrm{pH}$ ve iletkenlik değerleri oda sıcaklığında dijital pH metre (Orion 4-Star pH meter, Thermo Scientific, ABD) ve iletkenlik ölçer (Mettler Toledo S230, Switzerland) kullanılarak ölçülmüştür.

\subsubsection{Renk analizi}

Örneklerin renk analizi Konica-Minolta CR-400 (Japonya) renk ölçer cihazı ve sıvı kabı kullanılarak yapılmıştır. Renk, L* (koyuluk-açıklık), a* (yeşillik-kırmızılık), b* (mavilik-sarılık) renk parametreleri cinsinden ifade edilmiştir. Ayrıca Hue açısı (h) ve Chroma (C) değerleri aşağıdaki eşitlikler ile hesaplanmıştır.

$$
\begin{aligned}
& h^{\circ}=\frac{180}{\pi} \tan ^{-1}(b / a) \\
& c=\sqrt{\left(a^{2}+b^{2}\right)}
\end{aligned}
$$

\subsubsection{Bulanıklk}

Örneklerdeki bulanıklık değeri ölçümü için örnek 95 mm yükseklik ve $25 \mathrm{~mm}$ çapa sahip örnek kabına yerleştirilmiş ve türbidimetre (Hach $2100 \mathrm{~N}$ Turbidimeter, A.B.D.) kullanılarak NTU (Nepholometric Turbidity Unit) değeri cinsinden belirlenmiştir (Tajchakavit ve ark. 2001).

\subsubsection{Toplam fenolik madde}

Toplam fenolik madde miktarı spektrofotometrik yöntemle belirlenmiştir. $\mathrm{Bu}$ amaçla, $0.5 \mathrm{~mL}$ örnek üzerine sirasıyla 2.5 $\mathrm{mL}$ Folin-Ciocalteu çözeltisi (saf su ile 10 kat seyreltilmiş) ve ( 0.5 ile $2 \mathrm{dk}$ arasında bekleme süresinden sonra) $2 \mathrm{~mL} \% 7.5$ 'lik sodyum karbonat $\left(\mathrm{Na}_{2} \mathrm{CO}_{3}\right)$ çözeltisi eklenmiştir. Elde edilen karışım vorteksle karıştırıldıktan sonra $50^{\circ} \mathrm{C}^{\prime}$ deki su banyosunda $5 \mathrm{dk}$ bekletilmiştir. Daha sonra oda sıcaklığına soğutularak spektrofotometrede (Thermo Scientific Evoluation 160 UV-Vis, ABD) $760 \mathrm{~nm}$ dalga boyunda absorbans, okunmuştur. Elde edilen absorbans değerleri gallik asit çözeltileri ile oluşturulan kurve yardımıyla g gallik asit eşdeğeri (GAE) L ${ }^{-1}$ esktrakta dönüştürülmüştür (Škerget ve ark. 2005).

\subsubsection{Istatiksel analizler}

Araştırma tesadüf parselleri deneme desenine göre iki tekerrürlü olarak gerçekleştirilmiş, analizler paralelli olarak yürütülmüştür. Ortalamalar varyans analizine tabi tutularak, önemli bulunan farklılıklar Duncan Çoklu Karşılaştırma Testi ile ortaya konulmuştur.

\section{Bulgular ve Tartışma}

Uygulamalara maruz kalan ekstraktlar \%4'lük katı sıv1 oran1 ile aynı ekstraksiyon şartlarına $\left(75^{\circ} \mathrm{C}, 30 \mathrm{dk} 500 \mathrm{~d} \mathrm{dk}^{-1}\right.$ karıştırma hızı) tabi tutularak elde edilmiş olsa da hibiskus ekstraklarının suda çözünür kuru madde içeriğinin $\left(2.3{ }^{\circ} \mathrm{Bx}\right)$ adaçayı ekstraktlarının suda çözünür kuru madde içeriğinden daha yüksek olduğu göze çarpmaktadır. Bu farklılığın en önemli nedeninin adaçayı ve hibiskus örneklerinin bileşimi ve fiziksel yapılarının farklılıklarından kaynaklandığı değerlendirilebilir. Nitekim düzenli zaman aralıkları ile $(5,10,15,20 \mathrm{dk})$ termal ve ultrases işlemi uygulanan örneklere ait $\mathrm{pH}$, iletkenlik, bulanıklık ve toplam fenolik madde içeriği sonuçları (Şekil 1-4) incelendiğinde bu farklılık daha net anlaşılmaktadır. Bu kapsamda adaçayı örneklerinin pH değerlerinin 5.66 ile 5.73 arasında, hibiskus örneklerinin ise 2.28 ile 2.41 arasında değişim gösterdiği belirlenmiştir. Hibiskus örneklerinin adaçayı örneklerine kıyasla daha asidik karakterde olduğu görülmektedir. Bununla birlikte örneklerin $\mathrm{pH}$ değerlerinin genel olarak uygulanan (termal işlem $85^{\circ} \mathrm{C}$, ultrasonik banyo $0.031 \mathrm{~W} \mathrm{~mL}^{-1} \mathrm{AGY}$, problu ultrasonik sistem $1.337 \mathrm{~W} \mathrm{~mL}^{-1}$ AGY) işlem ve süreye bağlı olarak $(5,10,15,20 \mathrm{dk})$ önemli bir değişim göstermediği ifade edilebilir (Şekil 1). Dinçer (2020) $1.4{ }^{\circ} \mathrm{Bx}$ seviyesinde suda çözünür kuru madde içeriğine sahip adaçayı ekstraktlarını farklı yöntemler ile konsantre ettiğ $i$ çalışmasında benzer şekilde örneklerin pH değerlerinin 5.66 ile 5.76 aralığında tespit edildiğini rapor etmiştir. Chumsri ve ark. (2008) taze ve kurutulmuş hibiskus çanak yapraklarını suda farklı sıcaklık $\left(50,60^{\circ} \mathrm{C}\right)$, süre $(30,60 \mathrm{dk})$ ve kat1/çözücü oranlarında $(1 / 5,1 / 10)$ ekstrakte ettiği çalışmalarında, örneklerin $\mathrm{pH}$ değerinin 2.79 ile 2.95 , toplam çözünebilir katı madde miktarının ise 5.33-9.80 briks arasında belirlendiğini bildirilmişlerdir. Ramirez-Rodrigues ve ark. (2011) $1 / 40$ katı/çözücü oranı ve $25^{\circ} \mathrm{C}$ 'de $30,60,120$ ve $240 \mathrm{dk}$ ile $90^{\circ} \mathrm{C}$ 'de $2,4,8,16 \mathrm{dk}$ olmak üzere farklı sicaklık ve sürelerde 


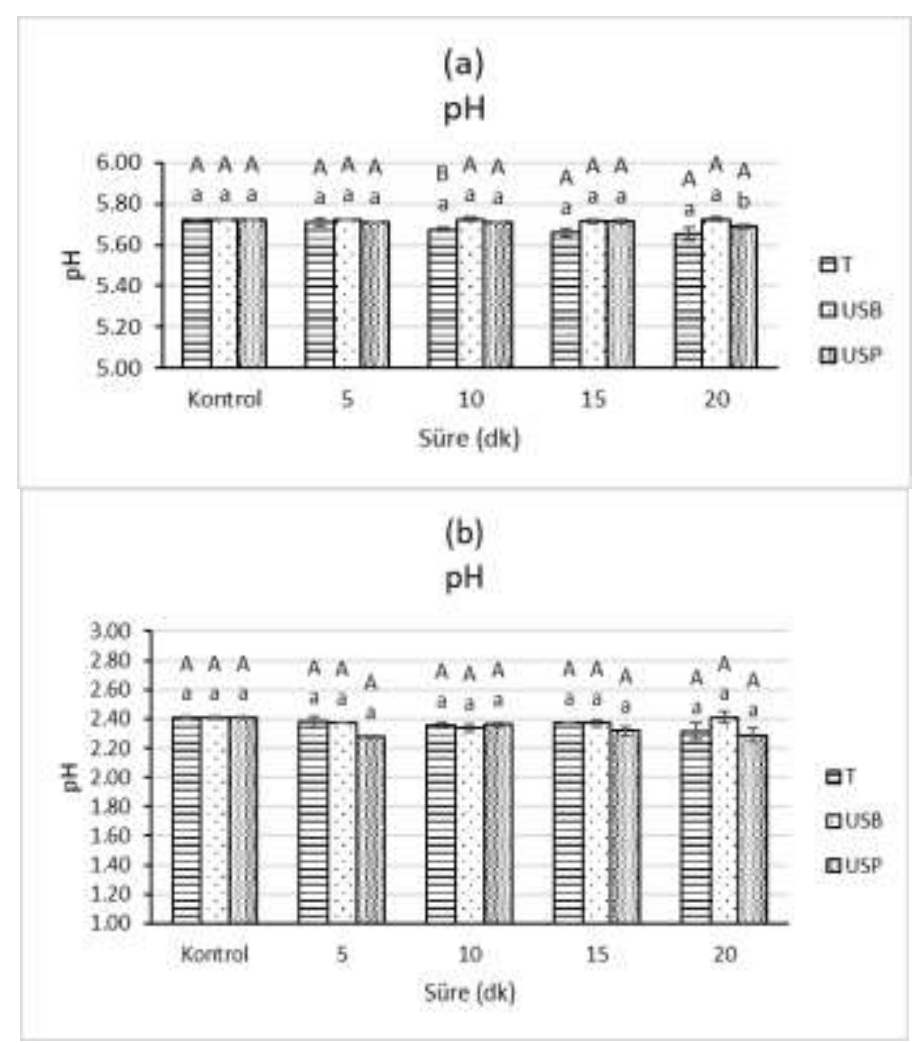

Şekil 1. Farklı yöntemler ile muamele edilen adaçayı (a) ve hibiskus (b) örneklerin zamana bağlı pH değerleri. T: Termal uygulama, $85^{\circ} \mathrm{C}^{\prime} \mathrm{de}, \mathrm{USB}$ : Ultrasonik uygulama, su banyosunda, $0.031 \mathrm{~W} \mathrm{~mL}^{-1} \mathrm{AGY}$, USP: Ultrasonik uygulama, Problu sistemde, $1.337 \mathrm{~W} \mathrm{~mL}^{-1} \mathrm{AGY}$. Aynı süredeki farklı büyük harfler metotlar arası farkın istatistiksel olarak önemli olduğunu gösterir. Ortalama değerler \pm standart hata. Aynı desendeki farklı küçük harfler aynı metotda süreler arası farkın istatistiksel olarak önemli olduğunu gösterir.

Figure 1. Time-dependent $\mathrm{pH}$ values of sage (a) and hibiscus (b) extracts treated with different methods. T: Thermal treatment at $85^{\circ} \mathrm{C}, \mathrm{USB}$ : Ultrasonic treatment in water bath at $0.031 \mathrm{~W} \mathrm{~mL}^{-1} \mathrm{APD}$, USP: Ultrasonic treatment with Probe system at $1.337 \mathrm{~W} \mathrm{~mL}^{-1}$ APD. Different capital letters on the same time represent that the difference between the different methods is statistically significant. Mean values \pm standard error. Different lower case letters in the same pattern represent that the difference between time periods is statistically significant in the same method.

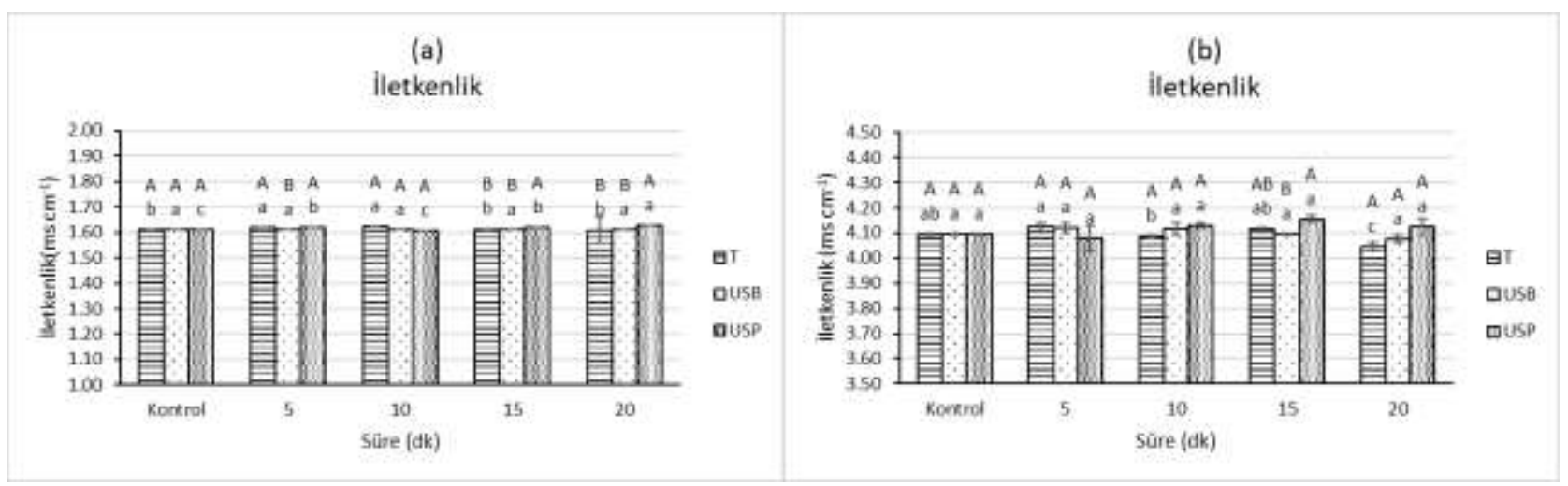

Şekil 2. Farklı yöntemler ile muamele edilen adaçayı (a) ve hibiskus (b) örneklerin zamana bağlı iletkenlik değerleri. T: Termal uygulama, $85^{\circ} \mathrm{C}$ 'de, USB: Ultrasonik uygulama, su banyosunda, $0.031 \mathrm{~W} \mathrm{~mL}^{-1} \mathrm{AGY}$, USP: Ultrasonik uygulama, Problu sistemde, $1.337 \mathrm{~W} \mathrm{~mL}^{-1} \mathrm{AGY}$. Aynı süredeki farklı büyük harfler metotlar arası farkın istatistiksel olarak önemli olduğunu gösterir. Ortalama değerler \pm standart hata. Aynı desendeki farklı küçük harfler aynı metotda süreler arası farkın istatistiksel olarak önemli olduğunu gösterir.

Figure 2. Time-dependent conductivity values of sage (a) and hibiscus (b) extracts treated with different methods. $T$ : Thermal treatment at $85^{\circ} \mathrm{C}$, USB: Ultrasonic treatment in water bath at $0.031 \mathrm{~W} \mathrm{~mL}^{-1} \mathrm{APD}$, USP: Ultrasonic treatment with Probe system at $1.337 \mathrm{~W} \mathrm{mL^{-1 }} \mathrm{APD}$. Different capital letters on the same time represent that the difference between the different methods is statistically significant. Mean values \pm standard error. Different lower case letters in the same pattern represent that the difference between time periods is statistically significant in the same method. 


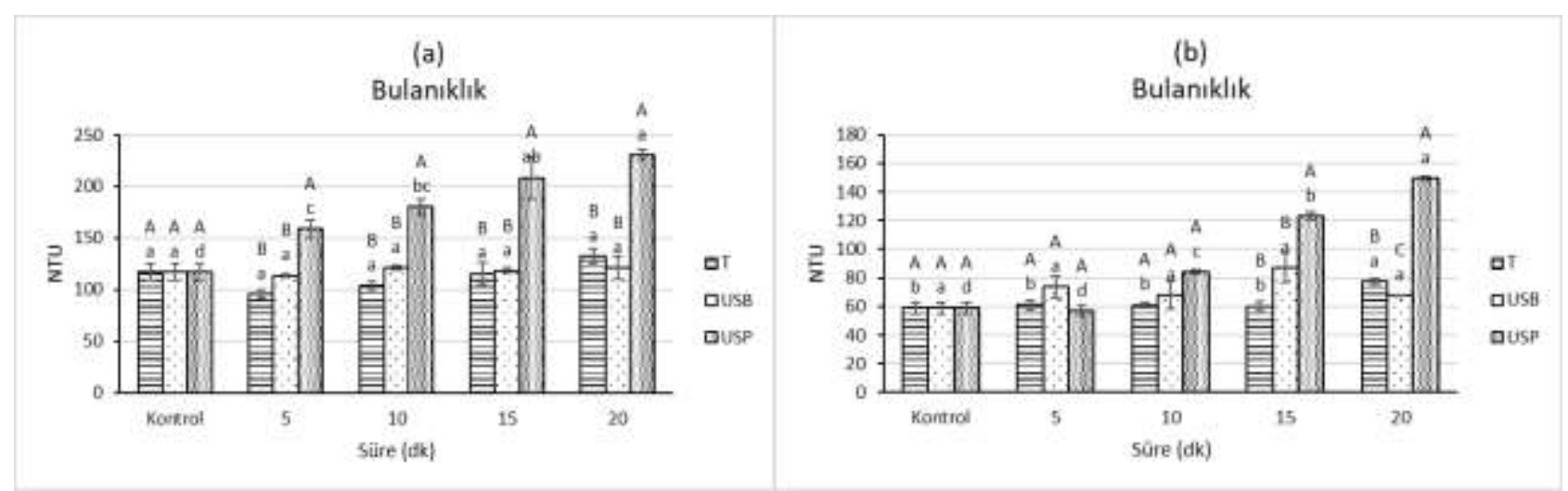

Şekil 3. Farklı yöntemler ile muamele edilen adaçayı (a) ve hibiskus (b) örneklerin zamana bağlı bulanıklık değerleri. T: Termal uygulama, $85^{\circ} \mathrm{C}$ 'de, USB: Ultrasonik uygulama, su banyosunda, $0.031 \mathrm{~W} \mathrm{~mL}^{-1}$ AGY, USP: Ultrasonik uygulama, Problu sistemde, $1.337 \mathrm{~W} \mathrm{~mL}^{-1}$ AGY. Aynı süredeki farklı büyük harfler metotlar arası farkın istatistiksel olarak önemli olduğunu gösterir. Ortalama değerler \pm standart hata. Aynı desendeki farklı küçük harfler aynı metotda süreler arası farkın istatistiksel olarak önemli olduğunu gösterir.

Figure 3. Time-dependent turbidity values of sage (a) and hibiscus (b) extracts treated with different methods. T: Thermal treatment at $85^{\circ} \mathrm{C}, \mathrm{USB}$ : Ultrasonic treatment in water bath at $0.031 \mathrm{~W} \mathrm{~mL}^{-1}$ APD, USP: Ultrasonic treatment with Probe system at $1.337 \mathrm{~W} \mathrm{~mL}^{-1}$ APD. Different capital letters on the same time represent that the difference between the different methods is statistically significant. Mean values \pm standard error. Different lower case letters in the same pattern represent that the difference between time periods is statistically significant in the same method.

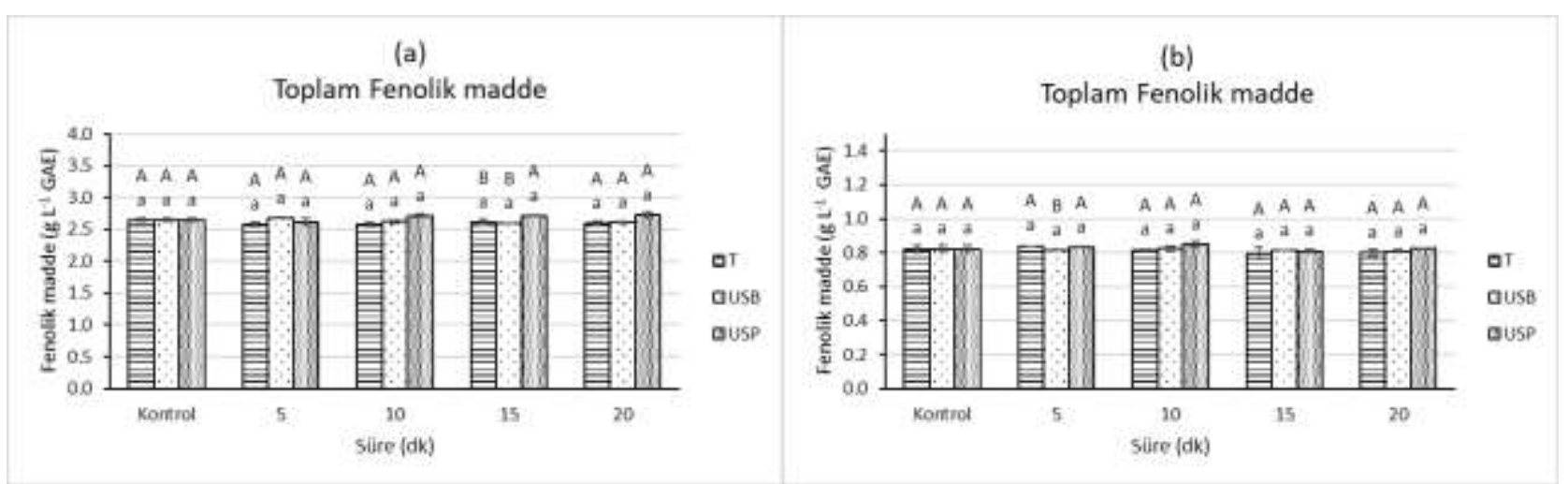

Şekil 4. Farklı yöntemler ile muamele edilen adaçayı (a) ve hibiskus (b) örneklerin zamana bağlı toplam fenolik madde içeriği. T: Termal uygulama, $85^{\circ} \mathrm{C}$ 'de, USB: Ultrasonik uygulama, su banyosunda, $0.031 \mathrm{~W} \mathrm{~mL}^{-1} \mathrm{AGY}$, USP: Ultrasonik uygulama, Problu sistemde, $1.337 \mathrm{~W} \mathrm{~mL}^{-1} \mathrm{AGY}$. Aynı süredeki farklı büyük harfler metotlar arası farkın istatistiksel olarak önemli olduğunu gösterir. Ortalama değerler \pm standart hata. Aynı desendeki farklı küçük harfler aynı metotda süreler arası farkın istatistiksel olarak önemli olduğunu gösterir.

Figure 4. Time-dependent total phenolic content of sage (a) and hibiscus (b) extracts treated with different methods. T: Thermal treatment at $85^{\circ} \mathrm{C}$, USB: Ultrasonic treatment in water bath at $0.031 \mathrm{~W} \mathrm{~mL}^{-1} \mathrm{APD}$, USP: Ultrasonic treatment with Probe system at $1.337 \mathrm{~W} \mathrm{~mL}^{-1} \mathrm{APD}$. Different capital letters on the same time represent that the difference between the different methods is statistically significant. Mean values \pm standard error. Different lower case letters in the same pattern represent that the difference between time periods is statistically significant in the same method.

gerçekleştirdikleri çalışmada; pH değerini 2.31-2.37 arasında, toplam katı miktarını $0.68-1.08 \mathrm{~g} 100 \mathrm{~mL}^{-1}$ ekstrakt aralığında bildirmişlerdir. Dinçer ve ark. (2020) ise farklı yöntemler ile 1.1 ${ }^{\circ} \mathrm{Bx}$ seviyesine kadar ekstrakte ettikleri hibiskus örneklerinde pH değerinin 2.41-2.42 arasında olduğunu bildirmiş̧lerdir.

Şekil 2'de sunulan iletkenlik sonuçları incelendiğinde adaçayı örneklerinin iletkenlik değerleri 1.61 ile $1.63 \mathrm{~ms} \mathrm{~cm}^{-1}$ arasında seyrederken hibiskus örneklerinde bu değer 4.05 ile $4.16 \mathrm{~ms} \mathrm{~cm}^{-1}$ arasında belirlenmiştir. Hibiskus örneklerinin suda çözünür kuru madde sonuçlarına paralel olarak iletkenlik değerlerinin de adaçayı örneklerinden daha yüksek olduğu görülmektedir. Ayrıca proses ve uygulama sürelerine bağlı olarak istatistiki açıdan bazı farklılıklar belirlenmesine rağmen bu sonuçların artış ya da azalıș şeklinde anlamlı bir eğilimi ifade etmediği görülmektedir (Şekil 2).
Uygulamalar sonucu en önemli değișimin problu ultrases sistemi ile muamele edilen örneklerin bulanıklık değerlerinde olduğu görülmektedir (Şekil 3). Adaçayı kontrol örneğinde 117 NTU olarak belirlenen bulanıklık değerinin problu ultrases sistemi ile $20 \mathrm{dk}$ 'llk uygulama sonucu yaklaşık 2 kat artarak 230 NTU değerine, hibiskus kontrol örneğinde ise 58.95 NTU olarak belirlenen bulanıklık değerinin yaklaşık 2.5 kat artarak 153.6 NTU'ya ulaştığı belirlenmiştir. Bununla birlikte termal yöntem ile $85^{\circ} \mathrm{C}$ 'de muamele edilen örnekler ile ultrasonik banyoda muamele edilen örneklerin bulanıklık değerlerinde zamana bağlı olarak önemli bir artış seyri gözlenmemiştir. Problu ultrases sitemindeki örneklerin bulanıklık değerlerinde zamana bağlı önemli $(P<0.05)$ bir artış belirlenirken ultrasonik banyodaki örneklerde böyle bir artış görülmemesi uygulanan ultrases işleminin gücü ile ilişsilendirilebilir. Zira ultrasonik banyodaki işlemin Akustik Güç Yoğunluğu $0.031 \mathrm{~W} \mathrm{~mL}-1$, 
problu ultrasonik sistemin ise $1.337 \mathrm{~W} \mathrm{~mL}^{-1}$ AGY olarak hesaplanmıştır. Örneklerde ultrases uygulamasıyla meydana gelen bulanıklık artışı genellikle kavitasyon olgusuyla ilişkilendirilmektedir. Kavitasyon süresince noktasal da olsa meydana gelen yükssek sıcaklık ve basınç değişimleri büyük moleküllerin daha küçük olanlara parçalanmasına neden olmaktadır. Bu da asılı partikül sayısında artışa neden olmakta, yüzey alanının genişlemesiyle partiküller arasındaki mesafe kısalmakta ve böylece çözelti bulanıklığı artabilmektedir (Dinçer ve Topuz 2015).

Adaçayı örneklerinde toplam fenolik madde içeriği 2.58-2.71 g L $\mathrm{L}^{-1}$ GAE arasında belirlenirken, hibiskus örneklerinde ise 0.80 ile $0.84 \mathrm{~g} \mathrm{~L}^{-1} \mathrm{GAE}$ arasinda tespit edilmiştir (Şekil 4). Hibiskus örneklerinin suda çözünür kuru madde ve iletkenlik değerleri adaçayından daha yüksek belirlenmesine rağmen adaçayı örneklerinin toplam fenolik madde açısından daha zengin olduğu dikkat çekmektedir.

Örneklerin renk ölçüm sonuçları (Çizelge 1-2) incelendiğinde uygulamalar $\mathrm{L}^{*}, \mathrm{a}^{*}, \mathrm{~b}^{*}, \mathrm{C}, \mathrm{h}$ renk değerlerinden bir kısmında istatistiki açıdan bazı farklılıklara neden olsa da bu etkinin artış ya da azalış şeklinde belirgin bir eğilim göstermediği anlaşılmaktadır.

Çizelge 1. Farklı yöntemler ile muamele edilen adaçayı ekstraktlarının renk değerleri.

Table 1. Color values of sage extracts treated with different methods.

\begin{tabular}{llccccc}
\hline Yöntem & \multicolumn{1}{c}{ Süre (dk) } & \multicolumn{1}{c}{$\mathrm{L}^{*}$} & $\mathrm{a}^{*}$ & $\mathrm{~b}^{*}$ & $\mathrm{C}$ & $\mathrm{h}$ \\
\hline $\mathrm{T}$ & Kontrol & $18.98 \pm 0.06^{\mathrm{aA}}$ & $1.14 \pm 0.14^{\mathrm{abA}}$ & $3.86 \pm 0.08^{\mathrm{aA}}$ & $4.02 \pm 0.11^{\mathrm{aA}}$ & $73.53 \pm 1.64^{\mathrm{abA}}$ \\
& 5 & $18.85 \pm 0.13^{\mathrm{abA}}$ & $1.33 \pm 0.05^{\mathrm{aA}}$ & $4.08 \pm 0.08^{\mathrm{aA}}$ & $4.29 \pm 0.09^{\mathrm{aA}}$ & $72.02 \pm 0.29^{\mathrm{bA}}$ \\
& 10 & $18.62 \pm 0.05^{\mathrm{bcC}}$ & $0.96 \pm 0.06^{\mathrm{bcA}}$ & $3.47 \pm 0.14^{\mathrm{bB}}$ & $3.60 \pm 0.15^{\mathrm{bB}}$ & $74.53 \pm 0.31^{\mathrm{abA}}$ \\
& 15 & $18.51 \pm 0.01^{\mathrm{cB}}$ & $0.82 \pm 0.02^{\mathrm{cA}}$ & $3.37 \pm 0.06^{\mathrm{bB}}$ & $3.46 \pm 0.06^{\mathrm{bA}}$ & $76.38 \pm 0.07^{\mathrm{aA}}$ \\
& 20 & $18.53 \pm 0.04^{\mathrm{cB}}$ & $0.85 \pm 0.02^{\mathrm{cB}}$ & $3.39 \pm 0.02^{\mathrm{bB}}$ & $3.50 \pm 0.03^{\mathrm{bB}}$ & $75.96 \pm 0.16^{\mathrm{aA}}$ \\
\hline USB & Kontrol & $18.98 \pm 0.06^{\mathrm{aA}}$ & $1.14 \pm 0.14^{\mathrm{aA}}$ & $3.86 \pm 0.08^{\mathrm{aA}}$ & $4.02 \pm 0.11^{\mathrm{AA}}$ & $73.53 \pm 1.64^{\mathrm{aA}}$ \\
& 5 & $18.94 \pm 0.12^{\mathrm{aA}}$ & $1.19 \pm 0.03^{\mathrm{aA}}$ & $4.11 \pm 0.31^{\mathrm{aA}}$ & $4.28 \pm 0.29^{\mathrm{aA}}$ & $73.78 \pm 1.52^{\mathrm{aA}}$ \\
& 10 & $19.01 \pm 0.00^{\mathrm{aB}}$ & $1.21 \pm 0.02^{\mathrm{aA}}$ & $4.21 \pm 0.03^{\mathrm{aA}}$ & $4.38 \pm 0.03^{\mathrm{aA}}$ & $74.02 \pm 0.15^{\mathrm{aA}}$ \\
& 15 & $18.72 \pm 0.11^{\mathrm{aB}}$ & $1.10 \pm 0.13^{\mathrm{aA}}$ & $3.73 \pm 0.13^{\mathrm{aAB}}$ & $3.88 \pm 0.16^{\mathrm{AA}}$ & $73.68 \pm 1.22^{\mathrm{aA}}$ \\
& 20 & $18.96 \pm 0.16^{\mathrm{aA}}$ & $1.16 \pm 0.04^{\mathrm{aA}}$ & $4.01 \pm 0.12^{\mathrm{aA}}$ & $4.18 \pm 0.14^{\mathrm{aA}}$ & $73.87 \pm 0.11^{\mathrm{aB}}$ \\
\hline USP & Kontrol & $18.98 \pm 0.06^{\mathrm{cdA}}$ & $1.14 \pm 0.14^{\mathrm{aA}}$ & $3.86 \pm 0.08^{\mathrm{aA}}$ & $4.02 \pm 0.11^{\mathrm{aA}}$ & $73.53 \pm 1.64^{\mathrm{aA}}$ \\
& 5 & $18.76 \pm 0.08^{\mathrm{dA}}$ & $1.02 \pm 0.12^{\mathrm{aA}}$ & $3.44 \pm 0.17^{\mathrm{aA}}$ & $3.59 \pm 0.19^{\mathrm{aA}}$ & $73.47 \pm 1.10^{\mathrm{aA}}$ \\
& 10 & $19.27 \pm 0.02^{\mathrm{abA}}$ & $0.90 \pm 0.07^{\mathrm{aA}}$ & $4.01 \pm 0.01^{\mathrm{aA}}$ & $4.10 \pm 0.01^{\mathrm{aA}}$ & $77.35 \pm 0.95^{\mathrm{aA}}$ \\
& 15 & $19.42 \pm 0.10^{\mathrm{aA}}$ & $0.99 \pm 0.00^{\mathrm{aA}}$ & $4.14 \pm 0.19^{\mathrm{aA}}$ & $4.26 \pm 0.18^{\mathrm{aA}}$ & $76.53 \pm 0.62^{\mathrm{aA}}$ \\
& 20 & $19.18 \pm 0.02^{\mathrm{bcA}}$ & $1.19 \pm 0.07^{\mathrm{aA}}$ & $4.20 \pm 0.17^{\mathrm{aA}}$ & $4.36 \pm 0.18^{\mathrm{aA}}$ & $74.26 \pm 0.20^{\mathrm{aB}}$ \\
\hline
\end{tabular}

T: Termal uygulama, $85^{\circ} \mathrm{C}^{\prime}$ de, USB: Ultrasonik uygulama, su banyosunda, $0.031 \mathrm{~W} \mathrm{~mL}^{-1}$ AGY, USP: Ultrasonik uygulama, Problu sistemde, $1.337 \mathrm{~W} \mathrm{~mL}^{-1} \mathrm{AGY}$. Ayn sütundaki farklı küçük harfler aynı metotda süreler arası farkın istatistiksel olarak önemli $(P<0.05)$ olduğunu gösterir olduğunu gösterir. Ortalama değerıstandart hata. Aynı süredeki farklı büyük harfler metotlar arası farkın istatistiksel olarak önemli olduğunu gösterir.

$\mathrm{T}$ : Thermal treatment at $85^{\circ} \mathrm{C}$, USB: Ultrasonic treatment in water bath at $0.031 \mathrm{~W} \mathrm{~mL}^{-1} \mathrm{APD}$, USP: Ultrasonic treatment with Probe system at $1.337 \mathrm{~W} \mathrm{~mL} \mathrm{~L}^{-1} \mathrm{APD}$. Different lower case letters in the same column represent that the difference between time periods is statistically significant in the same method. Mean values \pm standard error.

Different capital letters on the same time represent that the difference between the different methods is statistically significant.

Çizelge 2. Farklı yöntemler ile muamele edilen hibiskus ekstraktlarının renk değerleri

Table 2. Color values of hibiscus extracts treated with different methods.

\begin{tabular}{|c|c|c|c|c|c|c|}
\hline Yöntem & Süre (dk) & $\mathrm{L}^{*}$ & $a^{*}$ & $\mathrm{~b}^{*}$ & $\mathrm{C}$ & $\mathrm{h}$ \\
\hline \multirow[t]{5}{*}{$\mathrm{T}$} & Kontrol & $17.24 \pm 0.03^{\mathrm{aA}}$ & $0.85 \pm 0.18^{\mathrm{aA}}$ & $2.32 \pm 0.06^{\mathrm{aA}}$ & $2.48 \pm 0.01^{\mathrm{aA}}$ & $69.88 \pm 4.50^{\mathrm{aA}}$ \\
\hline & 5 & $17.44 \pm 0.10^{\mathrm{aA}}$ & $0.77 \pm 0.11^{\mathrm{aA}}$ & $2.15 \pm 0.05^{\mathrm{aA}}$ & $2.28 \pm 0.08^{\mathrm{bA}}$ & $70.39 \pm 2.20^{\mathrm{aA}}$ \\
\hline & 10 & $17.62 \pm 0.05^{\mathrm{aA}}$ & $0.84 \pm 0.01^{\mathrm{aA}}$ & $2.12 \pm 0.00^{\mathrm{aA}}$ & $2.28 \pm 0.00^{\mathrm{bA}}$ & $68.37 \pm 0.34^{\mathrm{aA}}$ \\
\hline & 15 & $17.55 \pm 0.05^{\mathrm{aA}}$ & $1.08 \pm 0.02^{\mathrm{aA}}$ & $2.26 \pm 0.01^{\mathrm{aA}}$ & $2.50 \pm 0.01^{\mathrm{aA}}$ & $64.47 \pm 0.25^{\mathrm{aA}}$ \\
\hline & 20 & $17.62 \pm 0.18^{\mathrm{aA}}$ & $1.17 \pm 0.05^{\mathrm{aA}}$ & $2.29 \pm 0.05^{\mathrm{aA}}$ & $2.57 \pm 0.02^{\mathrm{aA}}$ & $62.87 \pm 1.41^{\mathrm{aA}}$ \\
\hline \multirow[t]{5}{*}{ USB } & Kontrol & $17.24 \pm 0.03^{\mathrm{aA}}$ & $0.85 \pm 0.18^{\mathrm{aA}}$ & $2.32 \pm 0.06^{\mathrm{aA}}$ & $2.48 \pm 0.01^{\mathrm{aA}}$ & $69.88 \pm 4.50^{\mathrm{aA}}$ \\
\hline & 5 & $17.41 \pm 0.11^{\mathrm{aA}}$ & $0.92 \pm 0.04^{\mathrm{aA}}$ & $2.13 \pm 0.04^{\mathrm{aA}}$ & $2.32 \pm 0.05^{\mathrm{aA}}$ & $66.64 \pm 0.38^{\mathrm{aA}}$ \\
\hline & 10 & $17.27 \pm 0.03^{\mathrm{aB}}$ & $0.79 \pm 0.07^{\mathrm{aA}}$ & $2.28 \pm 0.03^{\mathrm{aA}}$ & $2.42 \pm 0.01^{\mathrm{aA}}$ & $70.85 \pm 1.77^{\mathrm{aA}}$ \\
\hline & 15 & $17.29 \pm 0.05^{\mathrm{aB}}$ & $0.98 \pm 0.12^{\mathrm{aA}}$ & $2.19 \pm 0.05^{\mathrm{aA}}$ & $2.40 \pm 0.01^{\mathrm{aB}}$ & $65.97 \pm 2.90^{\mathrm{aA}}$ \\
\hline & 20 & $17.40 \pm 0.08^{\mathrm{aA}}$ & $0.99 \pm 0.03^{\mathrm{aA}}$ & $2.18 \pm 0.12^{\mathrm{aA}}$ & $2.40 \pm 0.12^{\mathrm{aA}}$ & $65.40 \pm 0.52^{\mathrm{aA}}$ \\
\hline \multirow[t]{5}{*}{ USP } & Kontrol & $17.24 \pm 0.03^{\mathrm{aA}}$ & $0.85 \pm 0.18^{\mathrm{aA}}$ & $2.32 \pm 0.06^{\mathrm{aA}}$ & $2.48 \pm 0.01^{\mathrm{aA}}$ & $69.88 \pm 4.50^{\mathrm{aA}}$ \\
\hline & 5 & $17.18 \pm 0.02^{\mathrm{aA}}$ & $1.03 \pm 0.05^{\mathrm{aA}}$ & $2.22 \pm 0.01^{\mathrm{aA}}$ & $2.45 \pm 0.03^{\mathrm{aA}}$ & $65.03 \pm 1.02^{\mathrm{aA}}$ \\
\hline & 10 & $17.22 \pm 0.04^{\mathrm{aB}}$ & $1.10 \pm 0.10^{\mathrm{aA}}$ & $2.28 \pm 0.08^{\mathrm{aA}}$ & $2.53 \pm 0.11^{\mathrm{aA}}$ & $64.26 \pm 1.32^{\mathrm{aA}}$ \\
\hline & 15 & $17.22 \pm 0.03^{\mathrm{aB}}$ & $1.06 \pm 0.05^{\mathrm{aA}}$ & $2.31 \pm 0.00^{\mathrm{aA}}$ & $2.54 \pm 0.02^{\mathrm{aA}}$ & $65.39 \pm 1.01^{\mathrm{aA}}$ \\
\hline & 20 & $17.30 \pm 0.04^{\mathrm{aA}}$ & $1.17 \pm 0.24^{\mathrm{aA}}$ & $2.13 \pm 0.21^{\mathrm{aA}}$ & $2.45 \pm 0.07^{\mathrm{aA}}$ & $61.09 \pm 7.28^{\mathrm{aA}}$ \\
\hline
\end{tabular}

T: Termal uygulama, $85^{\circ} \mathrm{C}^{\prime} \mathrm{de}$, USB: Ultrasonik uygulama, su banyosunda, $0.031 \mathrm{~W} \mathrm{~mL}^{-1} \mathrm{AGY}$, USP: Ultrasonik uygulama, Problu sistemde, $1.337 \mathrm{~W} \mathrm{~mL}^{-1} \mathrm{AGY}$.Ayn1 sütundaki farklı küçük harfler aynı metotda süreler arası farkın istatistiksel olarak önemli $(\mathrm{P}<0.05)$ olduğunu gösterir olduğunu gösterir. Ortalama değerıstandart hata. Aynı süredeki farklı büyük harfler metotlar arası farkın istatistiksel olarak önemli olduğunu gösterir.

$\mathrm{T}$ : Thermal treatment at $85^{\circ} \mathrm{C}$, USB: Ultrasonic treatment in water bath at $0.031 \mathrm{~W} \mathrm{~mL}^{-1} \mathrm{APD}$, USP: Ultrasonic treatment with Probe system at $1.337 \mathrm{~W} \mathrm{~mL}^{-1} \mathrm{APD}$. Different lower case letters in the same column represent that the difference between time periods is statistically significant in the same method. Mean values \pm standard error. Different capital letters on the same time represent that the difference between the different methods is statistically significant. 


\section{Sonuç}

Halk arasında bitki çayı olarak yaygın şekilde tüketilen adaçayı ve hibiskus gibi bitkiler, sahip oldukları aroma ve renk maddeleri nedeniyle farklı gıda ürünlerinde, özellikle de soğuk içeceklerde daha sık kullanılmaya başlanmıştır. Diğer taraftan söz konusu ürünlerin daha uzun süre muhafaza edilebilmeleri için uygulanan 1 sı1 işlemler ürünün 1sıya duyarlı bileşenlerine zarar verebilmekte, renk ve aromada istenmeyen değişikliklere neden olabilmektedir. $\mathrm{Bu}$ nedenle ultrases gibi 1sıl olmayan alternatif yöntemlere olan ilgi de artmıştır. Bu çalışmada, hazırlanan adaçayı ve hibiskus ekstraktlarına ultrasonik banyo ve problu sistemde olmak üzere iki farklı ultrases uygulaması ve $85^{\circ} \mathrm{C}$ 'de 1 sıl işlem uygulanmış ve bu örneklerde bazı kalite özellikleri değerlendirilmiştir. Genel olarak analiz sonuçları incelendiğinde uygulamaların bulanıklık değeri dışında önemli bir değişime neden olmadığı belirlenmiştir. Ancak bulanıklığın özellikle içeceklerde önemli bir parametre olarak değerlendirildiği göz ardı edilmemelidir. $\mathrm{Bu}$ nedenle, ürünlerin hedeflenen amaca yönelik olarak işlenmesinde kullanılacak yöntemin yanında, yöntemin uygulama şekli, güç ve süresinin, renk ve bulanıklık gibi fiziksel özellikler de göz önüne alınarak optimize edilmesi önem arz etmektedir.

\section{Kaynaklar}

Baser KHC (2002) Aromatic biodiversity among the flowering plant taxa of Turkey. Pure and Applied Chemistry 74(4): 527-545.

Baydar H (2005) Tibbi, Aromatik ve Keyf Bitkileri Bilimi ve Teknolojisi. Süleyman Demirel Üniversitesi, Isparta.

Chumsri P, Sirichote A, Itharat A (2008) Studies on the optimum conditions for the extraction and concentration of roselle (Hibiscus sabdariffa Linn.) extract. Songklanakarin Journal of Science \& Technology 30(1): 133-9.

Cid-Ortega S, Guerrero-Beltrán JA (2015) Roselle calyces (Hibiscus sabdariffa), an alternative to the food and beverages industries: a review. Journal of Food Science and Technology 52(11): 68596869.

Condón S, Raso J, Pagán R (2005) Microbial inactivation by ultrasound. In: Barbosa-Cánovas GV, Tapia SM, Cano MP (Ed.) Novel Food Processing Technologies. CRC Press, New York.

Da-Costa-Rocha I, Bonnlaender B, Sievers H, Pischel I, Heinrich M (2014). Hibiscus sabdariffa L.-A phytochemical and pharmacological review. Food Chemistry 165: 424-443.

Delamare APL, Moschen-Pistorello IT, Artico L, Atti-Serafini L, Echeverrigaray S (2007) Antibacterial activity of the essential oils of Salvia officinalis L. and Salvia triloba L. cultivated in South Brazil. Food Chemistry 100(2): 603-608.

Dinçer C, Topuz A (2018) Meyve suyu işlemede ultrases kullanımı. Gida 43(4): 569-581.

Dinçer C (2020) Adaçayı ekstraktlarının farklı yöntemler ile konsantrasyonunun matematiksel modellenmesi ve kalite özelliklerinin araştırılması. Gıda 45(4): 736-747.

Dinçer C, Tongur T, Erkaymaz T (2020) Farklı ekstraksiyon yöntemlerinin hibiskus ekstraktlarının kalite özellikleri üzerine etkisinin araştırılması. Gıda 45(3): 409-420.

Dinçer C, Topuz A (2015) Inactivation of Escherichia coli and quality changes in black mulberry juice under pulsed sonication and continuous thermosonication treatments. Journal of Food Processing and Preservation 39(6): 1744-1753.

El-Sayed NH, Khalifa TI, Ibrahim MT, Mabry TJ (2001) Constituents from Salvia triloba. Fitoterapia 72(7): 850-853.
Ergün AR, Baysal T, Bozkır H (2013) Ultrases yöntemi ile karotenoitlerin ekstraksiyonu. Gida 38(4): 239-246.

Gedik S (2014) Çukurova koşullarında farklı ekim zamanlarının kerkede (Hibiscus sabdariffa L.) bitkisinin çanak yaprak verimi ve kalitesine etkisi. Yüksek lisans Tezi, Çukurova Üniversitesi Fen Bilimleri Enstitüsü, Tarla Bitkileri Anabilim Dalı, Adana.

Gezek G, Hashemi P, Kalaycıŏlu Z, Kaygusuz H, Sarıŏlu G, Döker S, Dirmenci T, Erim FB (2019) Evaluation of some Turkish Salvia species by principal component analysis based on their vitamin B2, mineral composition, and antioxidant properties. LWT-Food Science and Technology 100: 287-293.

Lee H, Kim H, Cadwallader KR, Feng H, Martin SE (2013) Sonication in combination with heat and low pressure as an alternative pasteurization treatment-Effect on Escherichia coli K12 inactivation and quality of apple cider. Ultrasonics Sonochemistry 20(4): 1131-1138.

Piyasena P, Mohareb E, Mckellar RC (2003) Inactivation of microbes using ultrasound: a review. International Journal of Food Microbiology 87(3): 207-216.

Ramirez-Rodrigues MM, Plaza ML, Azeredo A, Balaban MO, Marshall MR (2011) Physicochemical and phytochemical properties of cold and hot water extraction from Hibiscus sabdariffa. Journal of Food Science 76(3): C428-C435.

Škerget M, Kotnik P, Hadolin M, Hraš AR, Simonič M, Knez Ž (2005) Phenols, proanthocyanidins, flavones and flavonols in some plant materials and their antioxidant activities. Food Chemistry 89(2): 191-198.

Şahin-Nadeem H, Dinçer C, Torun M, Topuz A, Özdemir F (2013) Influence of inlet air temperature and carrier material on the production of instant soluble sage (Salvia fruticosa Miller) by spray drying. LWT-Food Science and Technology 52(1): 31-38.

Tajchakavit S, Boye JI, Bélanger D, Couture R (2001) Kinetics of haze formation and factors influencing the development of haze in clarified apple juice. Food Research International 34(5): 431440.

Tepe B (2002) Lamiaceae familyasına ait bazı bitki türlerinin antimikrobiyal aktivitelerinin araştırılması. Yüksek Lisans Tezi, Cumhuriyet Üniversitesi Fen Bilimleri Enstitüsü, Sivas.

Tiwari BK, Mason TJ (2011) Ultrasound processing of fluid foods. In: Cullen PJ, Tiwari BK, Valdramidis V. (Ed.) Novel thermal and non-thermal technologies for fluid foods. Academic Press, Waltham.

Yağcıŏ̆lu P (2015) Farklı Ekstraksiyon Metotları ile Adaçayı (Salvia Officinalis L.) Bitkisinden Antioksidan Ekstraksiyonunun Optimizasyonu. Yüksek Lisans Tezi, İstanbul Teknik Üniversitesi Fen Bilimleri Enstitüsü Gıda Mühendisliği Anabilim Dalı, İstanbul. 